\title{
THE ALTERNATION OF DESU/-MASU WITH PLAIN FORM SPEECH AND THE CONSTITUTION OF SOCIAL CLASS IN JAPANESE HIGH SCHOOL ENGLISH LESSONS
}

\author{
Sarah S. Meacham
}

\begin{abstract}
This article explores the alternation of honorific language (desu/-masu) and plain form language within English language lessons in Japanese high schools. It argues that, within such educational contexts, alternation of these different ways of speaking are perspective-shifting routines, to which their indexical meanings are related. I suggest that in a liberal arts high school, the alternation of forms amounts to an analytical practice within which desu/-masu highlights abstract knowledge and plain form frames participants' involvement in imaginary event situations within which the contingent use of English can be theorized. In contrast, in a technical high school, the alternation of forms amounts to an identity problematizing practice, in which desu/-masu indexes a speaker's intrapersonal distance from typical "school-like" roles and activities, and plain form indexes an authentic, Japanese insider identity in the face of learning English. These different perspective-taking routines socialize very different relationships between self and school, and, in particular, between self and resources such as second language proficiency, and are thus an arena for the reproduction of social class distinctions.
\end{abstract}

Keywords: Japanese; Honorific language; Socio-economic class; Classroom interaction.

\section{Introduction}

In this article I explore the mixing of honorific desu/-masu form and non-honorific plain or abrupt form during English language lessons in Japan. I argue that the routine alternation of these forms within mundane classroom interaction amounts to perspective-shifting practices that, in their different implementations, reflect and constitute different social class identities. Therefore, in addition to a contribution to the literature on contextually-situated style shifting between desu/-masu and plain form in Japanese, this paper seeks to show how English language learning is an arena for the reproduction of social class differences in Japanese society.

Data were collected in conjunction with ethnographic fieldwork over the course of a year in two Tokyo public high schools named Liberal Arts High School (LAHS) 
and Technical High School (THS) for this study. ${ }^{1}$ Students at LAHS, which is located in upscale Western Tokyo, are being prepared for entrance exams to Japan's elite universities and for application to good foreign universities as well. Students at THS, located in a working class part of Tokyo known as shitamachi (downtown), is preparing its students for a more diverse set of paths: University, enrollment in two year technical colleges, or immediate entrance into the workforce.

Education is a site for the reproduction of social class differences across societies, as many have discussed (Bernstein 1971; Giroux 1981, 1983; Willis 1977). This is accomplished through tracking within and among schools, separate curricula, and forms of classroom interaction which reproduce the unequal relationships of society at large. However, Japanese education and society are often described as meritocratic and overwhelmingly middle class. Indeed, in the late 19th century and again in the postwar period, measures were taken to install an equal public education system, described as "single track" and available to all citizens regardless of wealth or family background (Ichikawa 1991). Studies have documented Japanese public school teachers' strong preparation and commitment to providing equal opportunities for students (Cummings 1980). Nevertheless, as some institutions have gained reputations for better preparing students to pass college entrance examinations, public secondary schools have gradually become hierarchically ordered in the minds of the public, and a number of private preparatory schools now compete with the top public schools to send students to the best universities (Kariya and Dore 2006). As Kariya and Dore note, there is an increasingly strong correlation between the social class of students' families and whether they attend the top-ranked public and private schools (ibid: 145). Both schools discussed here are national level, public secondary institutions, but in the ranking of Japanese secondary schools, LAHS, as an institution which very successfully prepares students to pass elite university examinations, is considered a superior school. Students in many technical or vocational schools like THS are not denied the opportunity to take elite university examinations, but their curriculum, though the same in theory, is regarded as less rigorous in some of the key test-preparation areas such as English language. Moreover, LAHS is known as a school populated by students from highly educated, professional class families, many of whom have had the opportunity to live abroad. My research has shown that discrepencies in English language instruction across these institutions differently orient their participants not just with respect to English test-taking skills, but also with respect to a kind of cosmopolitan outlook (Meacham 2004, 2007). That is, discourse at LAHS emphasizes international careers and identities, while that at THS seems to stress the problematic fit between English language and Japanese culture.

The history of English language instruction in Japan has been dominated by a concern to balance knowledge about the outside with the maintenance of Japanese culture against outside symbolic threats. During the 1940's English programs were dropped from curricula. Even proponents of maintaining the study of English language during the war sought to differentiate the learning of English language for language's sake from what was called "English education," which was the study of English for the purpose of learning about cultural difference, and "an opportunity to bring out the

${ }^{1}$ The names of institutions and people have been changed. The data analyzed in this paper are excerpted from the total corpus, which includes field notes, audio-recorded interviews with participants, and approximately 120 hours of video-recorded situated activity in both schools over the course of a year. 
realization of the value of the learner's mother tongue and culture" (Ike 1995: 7), i.e. Japanese language and identity.

The broad curriculum of English language learning still reflects this tension between embrace and constraint. Both schools discussed here require students to take two different kinds of English lessons: Grammar and Oral Communication. The official goal of Grammar classes is translation and test preparation. Teachers ideally tune the content and form of their lessons to that of English grammar sections on past college entrance tests. In response to critiques that such classes treat the language as an object rather than a tool, Oral Communication classes were instituted to improve students' ability to speak English, but these also emphasize general "cultural" or "international" comparison themes. In the last decade the government has begun to promote English language learning at the elementary school level with the goal of promoting real communicative competence (Goto-Butler 2005).

This study follows others that document the relationship between the interactionally-mediated access to communicative resources and the reproduction of social class (Bernstein 1971; Blommaert 1992). My research suggests that different practices surrounding the alternation between levels of speech at LAHS and THS is an interesting site to trace this relationship. The data show that in both schools honorific and plain form ways of speaking are regularly mixed by participants during English lessons, and that, in many instances, their indexical values are the same. For example, in both settings Haruko Cook's "speaker-focused self-presentation," where the speaker uses honorific desu/-masu to act "in role," seems salient (1997, 1999). Furthermore, in both settings, shifts into plain form can foreground the subordinate, spontaneous, or more detailed status of the information being presented. However, significant contrasts in co-occurring aspects of context suggest that the alternation of honorific and plain form styles has different secondary indexical values (Ochs 1993) within the two different institutions. At LAHS, the routine mixing of forms constitutes an analytical problem-solving practice, characterized by a shifting between abstract (marked by desu/-masu) and concrete (marked by plain form) levels of information. At THS, it regularly constitutes an identity problematizing practice, characterized by a shifting between English teacher/learner identities (marked by desu/-masu) and an authentic insider - or "Japanese" - identity (marked by plain form). Thus, at LAHS interaction surrounding the teaching of English retains an impersonal, objective tone, whereas at THS it repeatedly emphasizes the emotional, personal implications of learning English as a Japanese person. At THS, classroom discourse assumes a shared cultural stance toward English that is problematic. These observations are in keeping with Basil Bernstein's distinction between elaborated and restricted codes in use in educational contexts (1971). I argue that English at LAHS is taught via a kind of elaborated code that is detailed, impersonal, and information-rich, while at THS it is taught via a restricted code emphasizing affect and group solidarity. So in addition to the objective and academic speech in Japanese to which LAHS students are being socialized, they are also being provided detailed access to English language. At THS, access to English language appears to be a secondary concern to the maintenance of the insiderness of the restricted code emphasizing an assumed, shared struggle. The differential deployment of desu/-masu and plain form shifting is key to the construction of these different codes.

These distinct roles for the mixing of desu/-masu and plain form in English classes in Japan are supported by the presence or absence of other interactional elements, in particular, forms for packaging or objectifying information (proximal 
nominalizer no and distal nominalizer koto), as well as interactional particles ne and yo, which convey or construct an affective alignment among participants. The frequent absence of $n e$ and yo in conjunction with plain form at LAHS and their frequent presence in conjunction with plain form at THS is an especially dramatic indicator of the very different indexical values of impersonal and personal stance constituted through this practice.

\section{Honorific (desu/-masu) and plain form in Japanese}

The use of honorific versus plain form verb endings in Japanese, like honorific registers in many languages, has been described as bearing a direct relationship with speakers' social status or as required by the act of saving face (Brown and Levinson 1987). Japanese scholars have since questioned the Western theoretical bias inherent in Brown and Levinson's universal theory of honorifics, especially as it requires the idea of a static and unitary self who intentionally selects a mode of speaking in order to convey certain stylistic effects, or the idea of a set vertical social structure that determines speech. Based upon the analysis of naturally occurring interaction in diverse contexts in Japan, scholars have identified as a folk notion the belief that honorific desu/-masu is strictly used in formal social contexts and non-honorific plain form in intimate or informal contexts (Cook 1997, 1999; Maynard 1991).

Agha (1993), in his discussion of Tibetan honorifics, however, argues that "the element of ideology is an irreducible component of the register phenomenon," without which the multi-layered meanings of honorific forms across various contexts are not possible. The ideology of desu/-masu in Japan is that it is viewed as indicating a formal, or soto 'outside', relationship (Shibatani 1990), while the use of plain form between speakers is regarded as indexing an informal or uchi 'inside' relationship" (Cook 1999). These are what Agha would call "historically inherited social ideologies" which set the "boundary conditions" that link meaning to form (1993: 132). An exploration of the boundary conditions of honorific and non-honorific speech in Japanese must take into account the relational cultural concept of uchi/soto (inside/outside), extensively explored in Jane M. Bachnik and Charles J. Quinn's edited volume on situated meaning in Japanese self, society, and language (Bachnik and Quinn 1994). It is a critical ideological context within which to understand the situated nature of social order in Japan, and the multi-layered and ambiguous meanings possible for words and ways of speaking. The concept of uchi/soto links parallel socio-cultural continua. That is, inside-outside implies other continua: Near-far, familiar-unfamiliar, concrete-abstract, intimate-distant, known-unknown, in-group-out-group, among others. These sets of relational concepts are ideologically linked, so that, for example, language practice within the home (an inside, uchi space) will be associated with expressive choices that move interactants close together and invoke familiarity, intimacy, or concreteness, whereas interactions one is involved in out in the community (an outside, soto space), say with a storekeeper with whom one is on unfamiliar terms, will be conceptually associated with expressive choices that convey distance or deference. In actual practice, however, use of honorific speech (ideologically considered a soto way of speaking) within $u c h i$ settings or activities regularly occurs, and must be interpreted according to the immediate context. It may indicate deference, humor, disapproval and any number of other meanings by invoking a contrast to the ideological expectation of 
the setting. Likewise, plain forms within expected formal settings can accomplish certain rhetorical qualities by their ideological association with nearness, familiarity, congruent view, or intimacy. The interpretation of desu/-masu and plain form can therefore be potentially expanded and made much more complex and multi-faceted within the broad and flexible frame of uchi/soto. I argue here that the multi-layered context of public school classrooms in Japan bring certain interpretations to the fore.

\begin{tabular}{|l|l|l|}
\hline & Honorific & Non-Honorific (Plain or Abrupt) \\
\hline Verb Clause & -masu (present) & -(r)u (present) \\
\hline & -masen (negative) & -nai (negative) \\
\hline & -mashita (past) & -ta (past) \\
\hline Nominal Clause & Noun desu (present) & Noun da (present) \\
\hline & Noun deshita (past) & Noun datta (past) \\
\hline & Noun deshou (inference) & Noun darou (inference) \\
\hline & & \\
\hline Adjectival Clause & A desu (present) & A-i (present) \\
\hline & A -katta desu (past) & A-katta (past) \\
\hline
\end{tabular}

Table 1: Honorific and Plain/Abrupt Forms in Japanese.

Exploration of the mixed use of desu/-masu and plain form by the same speaker during naturally occurring Japanese communication over the last few decades has strongly suggested that it is incredibly creative, constituting meaning differently within different contexts with respect to which its pragmatic role must be comprehended (Cook 1996; Dunn 1999, 2005; Geyer 2008; Ikuta 1982; Jones and Ono 2008; Maynard 1991). I combine two general theoretical perspectives that have arisen from this work in order to shed light on the mixture of honorific and plain form in English language learning settings. First, I employ Senko Maynard's delineation of the importance of mixed desu/masu and plain forms for the alternation of perspective and information status by a single speaker (1991). The importance of information status as a determinant of style is further supported by Cook's observation of the use of plain form during relatively spontaneous evaluation sequences in a t.v. interview that is otherwise characterized by official interview questions (1999), and by Geyer's observation that plain form in multiparty speech marks off-the-record, unofficial comments during otherwise planned, official discourse (2008). Second, I integrate Haruko Cook's findings, based on extensive research into naturally occurring Japanese interaction, that desu/-masu and plain forms are indexical and must be interpreted with reference to aspects of cooccurring context. Specifically, Cook's concepts of "speaker self-presentation" and "intra-personal distance and proximity" are salient in the context of both institutional settings discussed here $(1996,1997)$. Cook has shown how desu/-masu is often used at moments when speakers are acting authoritatively "in role," as a parent or teacher, for example.

I propose that, within classroom settings, the constitution of knowledge about English is simultaneously a constitution of social identity. As a habitual practice, the 
alternation of these forms during English language-learning activities socializes an interconnection among knowledge, language, and worldview over the long term (Capps and Ochs 1995; Ochs and Schieffelin 1984; Rogoff 1990; Sapir 1924). In the next two sections I discuss excerpts from naturally occurring teacher-student exchanges in English grammar lessons in order to argue for the highly situated indexical quality of the alternation of desu/-masu and plain form verbs. I then discuss briefly how these routines relate to the constitution of class-based ideologies concerning learning and English education.

\section{The constitution of problem solving perspective at liberal arts high school}

At Liberal Arts High School (LAHS), the routine alternation between desu/-masu and plain form constitutes a system of phenomenological modifications (Duranti 2009; Husserl 1989) to participants' perspective on English language as an object of analysis. Within this system, I propose that plain form appears to index a grounded, contingent, problem-solving stance while the use of desu/-masu appears to frame information as abstract and complete. The meanings of desu/-masu and plain form utterances in this situation are therefore constituted largely within a broad analytical framework rather than an interpersonal framework.

English grammar lessons at LAHS always take place in the homeroom classrooms, where the desks are lined up in rows and the teacher stands behind a tape player at a lectern at the front of the room. Lessons are largely conducted in Japanese, although some teachers may occasionally code-switch into English for short segments, and of course English words are referred to within Japanese utterances. Many lessons call for the playing of sustained segments of English from a tape recorder. There is a single teacher who calls on students to answer questions from a handout or a textbook in the format of the IRE (Initiation, Response, Evaluation) exchange (Mehan 1979). Students are called on either in order of their desks, moving from the front to the back, randomly, or sometimes according to a game format of some kind (e.g. the drawing of cards with students' names on them).

At the time of the following piece of interaction, the topic of the day's lesson was a discussion of "culture shock" as it might be experienced if one were doing a study year abroad. The material - both the voice on the tape recorder and the paper handout list in English all of the measures one can take to overcome culture shock and home sickness. The teacher, Iwasaki sensei, is eliciting Japanese translations of a given segment of speech on the tape recorder, as well as multiple transformations of the English sentences via the substitution of one or more words. In the following segment, Iwasaki sensei sums up the full English phrase that has been pieced together by student and teacher during the previous few turns at talk: Get to know the area where you live in. He then explains that "where" and "in which" can be substituted in the target sentence. Throughout this lecture segment, he uses only honorific forms desu/-masu (marked with a double underline), a typical default style for teacher lectures. Interactional particles $n e$ and yo are italicized. The distal nominalizer koto is also highlighted here (marked with a single underline). These co-occurring grammatical 
elements will be discussed below. Sensei is the word for "teacher" in Japanese, and is appended to ones name as a form of respectful reference. ${ }^{2}$

(1)

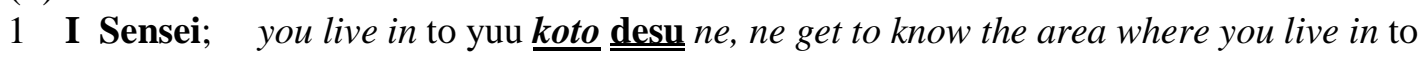
QT say Nom BE IP, IP yuu iikata mo kanou $\underline{\underline{\text { desu }}}$, ne ma koko de in ga tsuku to yuu $\underline{\text { koto }}$ ga where way of saying also possible BE IP here $S$ attached QT Nom S to no higai ni narimasu ne, ma kokorahen wa saishuuteki ni ato de with LK damage become IP, so this place $\mathrm{T}$ finally after matomemasu $n e$, ma where no tokoro wa in which o okikaeru koto mo organize IP, so LK $\overline{\text { place }} \mathrm{T} \quad \mathrm{O}$ replace Nom also dekimasu yo to, ne which wa shouryaku dekimasu yo to yuu you na tokoro be able IP QT, IP T omit be able IP QT like LK place $\underline{\underline{\text { desu}}}$, okay? dai san $\underline{\underline{\text { desu}}}$, $\mathrm{BE}, \quad$ three $\mathrm{BE}$

7 Tape Player; get familiar with the stores in the neighborhood...

1 I Sensei; it's "you live in," right, right saying it like, "get to know the area where you live in" is also possible, right, well here attaching "in" becomes incorrect with "where" right, so at this juncture finally we put it together right, so it's possible that "where" can replace "in which," right "which" can be omitted, there are places like that, okay? number three.

Tape Player; get familiar with the stores in the neighborhood...

The teacher's use of only desu/-masu to speak to his class in the above segment could be partially explained by the concept of "speaker-focused self-presentation" described by Cook (1999). As Cook explains, in many contexts the use of desu/-masu indexes high speaker self-awareness and the occupation of a role, as if "on stage," or in an official capacity. This is one possible layer of the explanation for the use of what appears to be deferential language by someone - a teacher - who is typically regarded as higher in status than his student addressees. Here, Iwasaki sensei is possibly indexing his role of "teacher." However, I argue that desu/-masu is also constituting an evidential framing, a role that is brought into focus only when the broader interactional context and subsequent interaction are taken into consideration.

\footnotetext{
${ }^{2}$ For glossing Japanese data the following abbreviations are used:

BE: various forms of copulative verb be

IO: indirect object marker

IP: interactional particle

LK: linker

NEG: negative morpheme

NOM: nominalizer

O: direct object marker

PASS: passive morpheme

Q: question marker

QT: quotative marker

S: subject marker

$\mathrm{T}$ : theme marker

$\mathrm{CON}$ : conditional marker

PRO: pronoun
} 
First, the content of Iwasaki's utterance is tightly related to the official incarnation of English in the voice of the tape recorder and on the handout students are looking at during the activity. These sources provide an ideal English. Koko de (here) in line 2 and kokorahen (around here) in line 3 explicitly locate these English words and their meanings within the text of the handout students are looking at and also temporally within the recording they listen to intermittently. With this official representation of English, which the teacher is merely giving voice to, the use of desu/-masu indexes an abstract, factual distance.

This sense is heightened by the co-occurrence of distal nominalizer koto, marked with a single underline in the excerpt above. Distal koto has been theorized to frame a concept as abstract or objectified, whereas proximal no is theorized as nominalizing an "event situation," framing a sense of concrete experiential immediacy (Maynard 1997). Maynard remarks, "In general, proximal framing is more suited for unplanned discourse, such as conversation, while distal framing is more useful for planned discourse, such as reading from a prepared script" (1997: 391). Throughout these data, as in example (1), the frequent co-occurrence of koto with desu/-masu verb morphology emphasizes the abstract and objectified, even "scripted," nature of the English information it frames. It nominalizes acts of speaking English as abstract concepts.

The role desu/-masu is playing in the constitution of an evidential framework is especially brought into relief when instances such as the above segment are viewed as one part of a larger routine during which participants alternate between honorific and plain form speech. A continuum of information status from abstract and complete to immediate and concrete emerges, and participants move back and forth along this continuum during class time. A subtle array of different theoretical perspectives on English language becomes apparent.

In this next excerpt from the same lesson, for example, a shift into plain form frames a different perspective on English. After listening to the third segment on the tape recorder, Iwasaki sensei shifts from desu/-masu to plain form (in line 3) when he calls on a student to answer a question. Note the use of proximal no nominalizer (marked with a single underline) during this segment of interaction, versus its complete absence during the first example (1). The lines marked with arrows define the portion of this segment where participants use plain form instead of honorific desu/-masu. Interactional particles are entirely absent during the plain form portion, but present in portions that include desu/-masu, where they are italicized.

1 Tape Player; ...three, do something you enjoy, call your family back home,

2 I Sensei; back home ne, eetto mae mo demashita keredomo, kore eetto Mr.

IP, uh before also came up however, this uh

- 3 Nakayama kore nan no imi (dai)? donna imi? (back) home, call your family, this what LK meaning $Q$ what meaning

- 4 Nakayama; (states)

- 5 I Sensei; (states) tte yuu ka kore wa call back home tte yuu no wa, tatoeba jibun ga QT Q this T ryuugaku shitetara, doko no koto itteru no? QT LK T, for example self $\mathrm{S}$ study abroad doing CON, where LK thing saying Q

7 Nakayama; ( ),

8 I Sensei; shiteiru ( ) datte, dakara jibun ga nihon ni ite, amerika ni ikuto, know but, so self S Japan IO exist, America IO go if/when, 
$9 \quad$ koko ni iru kara back da to

here IO exist so BE QT

10 Nakayama; jibun no kuni, oneself LK country

11 I Sensei; un, jibun no kuni tte $\underline{\text { koto }}$ ne ne, in his or in her country de ii desu $n e$, jibun uhuh, self LK country QT Nom IP IP good BE IP, self no kuni ni iru kazoku ni renraku shinasai tte yuu koto $\underline{\underline{\text { desu }}} n e$, ii desu ka? LK country IO exist family IO should call QT Nom BE IP good BE Q kono ( )bun, back home, mae ni mo ikkai demashita, this ( )piece before also one time came out

1 Tape Player; ...three, do something you enjoy, call your family back home,

2 I Sensei; "back home" right, uh this came up before too, but this uh Mr. Nakayama

- 3 what is the meaning of this? what meaning? "(back) home, call your family,"

- 4 Nakayama; (states),

- 5 I Sensei; (states)? this here saying "call back home", for example, if you yourself are

- 6 doing a study abroad, where is it that you are saying,

7 Nakayama; ( ),

- 8 I Sensei; I know but, therefore you yourself are in Japan, then you go to America, and

- 9 you are here then, if you say "back,"

- 10 Nakayama; your own country,

11 I Sensei; uhuh, it's to say your own country right right, "in his or in her country" is fine

12 right, it's to say that you should call your family that is back in your own

13 country, correct? this piece, "back home," came up once before too,

Iwasaki sensei begins by repeating a few words - back home - from the piece just heard on the tape recorder. He then points out, using desu/-masu, that this phrase "back home" - has appeared before (mae mo demashita - "came up earlier"). The shift into plain form begins in line 3 when he addresses a student individually. He calls on Mr. Nakayama to explain the meaning of "back home."

Some theories suggest that the contrast between desu/-masu and plain form in contexts where they are mixed is fundamentally a contrast between speech directed at an other (desu/-masu), and speech directed at the self (plain form). While the desu/masu form in this context could theoretically index speech to other (seeking alignment from a student audience), I argue that the plain form within this mixing context cannot be explained as self-addressed speech, or speaker orientation (see Maynard 1991, 1993). Alternatively, some linguists have theorized that plain form indexes a psychological closeness between interactants (Ikuta 1983; Shibatani 1990). But as Cook has argued, plain form is often used by teachers when they address an individual student in contrast to a whole class, not because of increased psychological closeness, but because at such moments they are less "on stage" (1999). Since shifts into plain form happen in conjunction with students' participation, that a teacher no longer feels "on stage" is one potential explanation.

However, none of these theories adequately captures the role of plain form within these English language-learning activities, though there are aspects of these explanations that are salient here. In Maynard's evaluation of the alternation between informal and formal verb morphology, for example, she points to the immediacy indexed by informal verb endings (1991). Moments of abruptness (plain form) in her data can suggest that the speaker has momentarily left the context of the interaction and 
taken "a perspective internal to the narrative setting," or presents "semantically subordinate" information (Maynard 1991: 551). The utterance is not "designed," as Maynard expresses it, but rather immediate.

I argue that focusing on the shift between forms, rather than the individual instances of either plain form or desu/-masu, yields a view of these grammatical tools as parts of evidential routines. Segments of talk that slip into plain form accomplish a momentary penetration into the details of English usage by situating both the student and English within imaginary contexts of use. This is often necessary in order to resolve confusion concerning language information presented more abstractly. In the above excerpt the student has provided an answer - "states" (meaning "United States") - for the meaning of "back home" that is incorrect given that the student is Japanese. Resolving this problem requires putting the student temporarily into the role of someone who is studying abroad and asking him to consider the use of the phrase from that perspective. This explains the sudden occurrence of the pronoun jibun (roughly, "oneself") in order to make clear that the student should answer based on this imaginary scenario in which he himself is living abroad. The co-occurrence of no to nominalize the act of saying "back home" (back home tte yuu no) here heightens the framing of an event situation in which the student utters this English phrase, albeit in an imaginary scenario. This new evidential perspective is very different from that taken in excerpt (1) where information about English is presented objectively. Therefore, this shift in perspective with plain form also lowers the sense of performance constructed by the "official" framing of correct English and affords useful mistakes.

After this kind of theoretical stance, the resumption of desu/-masu has the effect of framing the solved puzzle and ratifying an official answer that students should record as "correct." In the above, therefore, the correct answer that the student, Nakayama, has supplied, that "back home" refers to anyone's country of origin, is then framed in line 11 with desu/-masu.

Note that only excerpt (1) and the portions of (2) framed with desu/-masu feature the use of interactional particles. The portion of (2) where interactants have shifted to plain form features no interactional particles at all. Cook has theorized that using plain form without interactional particles stresses information content, and that when interactants do use interactional particles with plain form it foregrounds affect toward the addressee or the referent of talk $(1998,1999)$. So in the excerpt above, the absence of interactional particles foregrounds the information and backgrounds the interpersonal relationship, despite the fact that segments of plain form are the ones where both teacher and students interact. This heightens the sense of a kind of analytical apprenticeship where students and teacher are occupying a joint perspective to try to construct meaning. Distinctions among participants fall temporarily away. The use of interactional particles ne and yo (italicized in this excerpt) in excerpt (1), on the other hand, suggests that the teacher is addressee-focused and highlighting the authoritative transfer of information from himself to students. In both situations, alternation among forms is being used to frame and clarify different levels of information and to afford detailed problem-solving. Interpersonal and affective meaning is largely downplayed.

In the next example, featuring Watanabe sensei, a different English grammar teacher at LAHS, again we see how the sensei's initiation shifts out of formal desu/masu verb morphology and into plain form. Although the student's contributions below are inaudible, Watanabe Sensei responds to them with plain form verb endings. But once the answer has been completely and successfully provided, the sensei shifts back 
into desu/-masu to sum up or restate the answer. The lines marked with arrows define the portion of this segment where participants use plain form instead of honorific desu/masu.

1 W Sensei; hai, kore wa saisho no eeto, maegaki no you na bubun wo sashitemasu $n e$, yes this T last Nom uh preface LK like LK part O indicate IP eeto, chuui shite hoshii tokoro nikasho $\underline{\underline{\text { arimasu }}}$, 'The picture of arts' uh draw attention hope place two parts exist desu ne, ( ) wa ushiro kara setsumei shite ikimasu, hidari BE IP $\mathrm{T}$ back from explain going to left gawa mite kudasai, kouchi shuushoku no keiyoushi, aruiwa fukushi to kaite side look please here modifying LK adjective or adverbs QT write arimasu ga, jyaa reibun wo yonde kudasai, hai, douzo, Suzuki, exist but so example sentence $\mathrm{O}$ read please yes go ahead Suzuki

6 Suzuki; (reads English sentence, inaudible)

7 W Sensei; hai, saa, donna sora nan darou? ((points up))

8 yes well what sky what BE-suppose jyoukuu no ue ni aru sora wa,

9 Suzuki; (inaudible) upper skies LK above IO exist sky T

10 W Sensei; hai, yes fukai ai wa- fukai ao iro desu $n e$, deep blue $\mathrm{T}$ deep blue color BE IP

W Sensei; yes, this is the last one uh, it indicates a part that is like a preface, right 2 uh, there are two parts I hope to draw your attention to, it's 'the picture of 3 arts' right, I'm going to explain the ( ) from the back, please look on the 4 left-hand side, here there are written modifying adjectives or adverbs but, so 5 please read the example sentence, yes, go ahead, Suzuki, 6 Suzuki; (reads sentence, inaudible)

- 7 W Sensei; yes, so, what kind of sky do you suppose? ((points up))

- 8 the sky existing above the upper atmosphere,

9 Suzuki; (inaudible)

- 10 W Sensei; yes, ((hands out papers)) yes, deep blue, that's correct right, 11 deep blu- it's a deep blue color right,

Again a shift into plain form frames a proximal, imaginative stance with respect to the material. As though situated briefly within the narrative, the sensei gestures upward to the "sky" in line 7 in order to contextualize his question. This suggests a brief occupation of the place within the material where it is possible to imagine a potential sky above, "aru sora", "the sky existing." The plain form of line 10 ("fukai ao, sou da ne") is interesting because, despite summing up a correct answer and deploying an interactional particle $n e$, the teacher uses the plain form of the copula $d a$. Nevertheless, he then restates this summary using desu/-masu ("fukai ao iro desu ne"). Perhaps line 10 can be explained as a kind of intermediate position between the more experiential emphasis of the prior talk, and the abstract summation of subsequent utterances. Overall, however, a rough alternation between plain form and desu/-masu seems to routinely alternate situated and abstract perspectives on the material within these classrooms at LAHS. Plain form does not, in these examples, suggest an interpersonal 
frame, but rather, a problem-solving frame which brings participants closer to the details of the material.

The final example (4) below featuring Matsumoto Sensei, a third teacher at LAHS, is a piece of a very long segment during which he is leading his class in a very fast parsing of a recording and eliciting information from students concerning pieces of the text. Nearly the entire segment is characterized by plain form speech except, in line 8, when Matsumoto Sensei restates and summarizes the definition he asked the student, Yoshinoya, to read and uses an honorific form deshou (inferential form of desu/-masu). The arrow marks the sole instance of desu/-masu form used in this segment.

(4)

1 Tape Player; the Mayas made their balls out of solid rubber

2 M Sensei; osoraku ima Adachi ga yuu koto to kankei shiteru kana? they made their perhaps now Adachi S saying Nom with relate wonder balls out of solid rubber, rubber jitai wa ii yo ne? solid definition wo chotto situation T good IP IP O little itte moraou ka? ee Yoshinoya (toku) solid definition no tokoro wo yonde say receive $\mathrm{Q}$ uh Yoshinoya just LK place $\mathrm{O}$ read moraou ka na, "substance..." receive wonder,

6 Yoshinoya; substance (is) the factor of very hard

7 M Sensei; very hard or firm ne solid (5.0) butsuri nanka no kotoba dewa solid arui wa IP physics some LK word BE T or $\mathrm{T}$ solid substance ekitai ni taishite kotai to yuu no deshou $n e$ liquid IO contrast answer QT say Nom BE IP

1 Tape Player; The Mayas made their balls out of solid rubber

2 M Sensei; Perhaps now I wonder if this relates to what Adachi said? They made their balls out of solid rubber, the rubber situation is good huh? Can we get a quick definition of "solid"? Uh Yoshinoya, I wonder if you could read the

6 Yoshinoya; substance (is) the factor of very hard

7 M Sensei; very hard or firm right solid (5.0) it's a physics word solid or solid 8 substance, probably you could say as an answer that it is in contrast to liquid, right?

Much like the prior three examples, desu/-masu appears to mark a subtle shift in information status. It is used to restate and summarize an official and authoritative piece of information, here the definition of "solid" which the student has read from a piece of paper. In some ways, however, this segment complicates the theory supported by the prior three examples in that interactional particles ne and yo are used in conjunction with the plain form. Indeed, they are frequently used throughout this entire activity. One theory as to why this may be the case is that as students are quickly introduced to this text and recording, prior to a more thorough translation and analysis of it, the teacher is trying to involve students emotionally in the text, which features some rather gruesome facts about the ancient playing of soccer. Nevertheless, the interaction here remains on a very analytical level with the provision of detailed information about a much longer text. The interpersonal qualities imparted by the use of interactional particles is directed toward involving students in the meaning of the 
text. Desu/-masu appears once again to mark information that can be held up as official fact.

Lessons from Technical High School (THS) afford another context within which to inspect the situated meaning of the mixing of honorific verb morphology and plain form, and to illuminate how it instantiates a very different perspective-taking routine. I turn to these contexts in the next section.

\section{Problematizing the act of English language learning at technical high school}

At Technical High School (THS), as at LAHS, Cook's concept of intrapersonal distance is very salient (1999) and one interpretation of the use of honorific language is that it seems to index a "teacherly" role or frame actions that are overtly "school-like." Unlike at LAHS, however, honorific language rarely frames information as correct or abstract in character, and therefore does not seem to contribute to the clarification of information about English grammar. It appears instead to be part of a larger routine that draws attention to the act of learning itself. Within this perspective-alternating system, desu/masu seems to frame (often comically) learning English and other "school-like" activities, while plain form frames a more authentic self - an intrapersonal proximity in the face of learning English. The problematization of speaker identity thus comes to the foreground. Unlike at LAHS, at THS interactional particles like ne and yo are used frequently with plain form utterances that construct an empathetic and joint stance toward the effort and difficulty of learning English. In what follows I show examples that demonstrate these uses and the aspects of the co-occurring context that support these interpretations.

In the first segment from THS, Suzuki Sensei is explaining why she has decided to begin holding grammar class in the language laboratory where desks are equipped with computers and listening equipment. In this exchange, she uses plain form. She breaks off her explanation to take issue with the fact that students are talking amongst themselves rather than listening to her. In response to her plain form question, "kiiteru, kiiteru?" "((are you) listening?, (are you) listening?") delivered in an annoyed tone, a student responds in desu/-masu form: "Kiite maaasu!" ("(we're) liiistening!"). Instances of desu/-masu form are called out below (bolded and double underlined). Interactional particle yo is italicized.

1 S Sensei; tsukawasete ageru kara, mattete, dakara oto wo kiku no toka, gamen wo let use because, (I'm) waiting, so sound O listen Nom etc., video O miru no toka mo writing ni irete agetai $n a$ toka omottete, dakedo kotoshi yotsu watch Nom also IO insert want to give IP etc. thinking, but this year four

$3 \quad$ kurasu ga arukara, kiiteru, kiiteru? classes $\mathrm{S}$ exist so, listening, listening

4 Shuhei; kiiteru, kiite maaasu, listening, listening

5 S Sensei; boku toka kiite nai yo, PRO etc. not listening IP

6 Shuhei; haaai, kiite maasu, yes, listening 
1 S Sensei; because I want to let you use it, (I)'m waiting, so (I)'m thinking (I) want to fit

2 writing into listening to sound and video-watching etc., however, this year (I)

3 have four classes so- are you listening, are you listening?

4 Shuhei; listening, li::::stening,

5 S Sensei; you all are not listening,

6 Shuhei; ye:::s, (we)'re li::stening,

Based upon Maynard's contention that plain form often occurs in speakerfocused utterances, a likely explanation for plain form here is that Suzuki sensei is expressing her own thinking and her own decision to hold the class in this particular room ("So I'm thinking I want to fit writing into listening to sound and video-watching etc.") However, her use of plain form continues beyond this instance of self-reflection to the moment when she addresses a question to the class in line 3 ("Are you listening? Are you listening?").

Maynard has argued that humor and sarcasm are frequently expressed by the use of desu/-masu within contexts that are dominated by plain form (1991). This intepretation seems relevant here. In response to Suzuki Sensei's attempt to regain students' attention in line 3, a student, Shuhei, responds first in plain form and then with an elongated "(I)'m li::::stening" in line 4 that is produced in desu/-masu form. Suzuki Sensei then answers in plain form and uses an interactional particle yo which constructs an affective frame that has an intimate, scolding character. Here the use of desu/-masu, together with the prosodic features of the utterance, is an anomaly within the immediately surrounding plain form discourse and enables a humorous commentary on classroom activity. Instead of responding to the student's utterance with desu/-masu, Suzuki Sensei reasserts the plain form framework with which she typically addresses the class in moments when she is not acting in a teacherly role.

In what follows, I argue that this contrast is a contrast between the performance of school identity and a more authentic insider identity. I argue that it subtly intertwines with the typical evidential routine and indexes a kind of self-consciousness in the face of learning that does not appear to be overtly displayed within classes at LAHS.

Typically students at THS work on answering questions located in the textbook or on a handout, or they have a list of sentences to translate. After doing so, there is a whole-class activity during which Suzuki Sensei calls on students and they offer their answers. In the following excerpt Suzuki Sensei invites one student, Asou kun ${ }^{3}$, to explain the difference between the English words "study" and "learn." After Asou kun answers, Suzuki Sensei goes on to another student's contribution (that of Katou kun), before finally ratifying a correct answer. Arrows are used to mark the portion of the segment in plain form. Distal and proximal nominalization are identified (underlined, bolded, and italicized). Interactional particles are italicized.

(6)

1 ((some students are raising their hands))

2 S Sensei; hai jyaa oroshite $\underline{\underline{\text { kudasai}}}$, jaa ima Asou kun ga study to learn no chigai ni yes so lower please, so now Asou $\mathrm{S}$ and LK difference $\mathrm{P}$

4 Students; ooooooo, tsuite setsumei shimasu, hai, stand up ( ) hai, regarding explain, yes yes

\footnotetext{
${ }^{3} k u n$ is an address term used for young men.
} 
- 5 S Sensei; uso demo ii kara, incorrect although good because

- 6 Asou; ah, uso demo ii, aaa, eeetto, study tte yuu no wa jibun ga mizukara benkyou shite incorrect although good, uhh, umm, QT Nom T self S personally study

7 manabu koto de, learn tte yuu no wa, hito kara osowaru koto, learn Nom BE, QT Nom T, person from be taught Nom

8 S Sensei; osowaru, hai, arigatou, jaa, ushiro ikou, hai, Katou kun, be taught, yes, thanks, so, back let's go, yes, Katou,

9 Students; Katou, hahhahhaa,

- 10 Katou; $($ )

- 11 S Sensei; ( ) ka, sou yuu wake ni mo ikanai, Q, like say is impossible, study tte yuu no wa, benkyou suru koto nan desu nee,

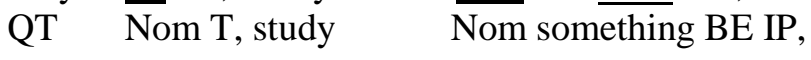

1 ((some students are raising their hands))

2 S Sensei; yes so please put them down, so now Asou kun will explain the difference

4 Students; ooooooo, between study and learn, yes, stand up ( ) yes,

5 S Sensei; it's okay if its not correct,

- 6 Asou; ah, it's okay if it's not correct, uh, ummm, to say "study" is you are studying and

7 learning it on your own, saying "learn" is you're being taught by someone,

- 8 S Sensei; being taught, yes, thanks, so, let's go to the back, yes, Katou kun, 9 Students; Katou, hahhahhaa,

10 Katou; ( )

- 11 S Sensei; ((repeats Katou with question intonation)), you can't say that, 12 to say "study" means "benkyou suru" or something right,

As at LAHS, shifts into plain form often accompany more detailed information about English. For example, in the above excerpt, beginning in line 6, Asou kun explains his understanding of the precise difference between "study" and "learn." In order to do so, he uses both proximal and distal nominalization to differentiate between an instance of the word and what that utterance would abstractly imply (Line 12). The absence of desu/-masu brings the informational content of the utterance to the fore. But unlike the examples from LAHS, students and teacher do not jointly shift to plain form in order to occupy a theoretical event situation that might help clarify the use of English.

In THS classroom routines, the primary role of the use of desu/-masu is to index a teacherly or school-like role. In the above excerpt, honorific kudasai and setsumei shimasu in lines 2 and 3 are used as the teacher is speaking to the whole class and describing school-like business: Asking students to put their hands down, and describing how one student will explain (setsumei shimasu) the difference between the English words "study" and "learn." Having rather formally framed activity this way, however, Suzuki Sensei then tells the student who will explain, Asou kun, to "stand up" in English. This prompts a somewhat mocking reaction on the part of the rest of the class in line 4. Then using plain form, Suzuki Sensei remarks, "uso de mo ii kara," which roughly translates as "it's alright if it's incorrect." This seems to undercut the performative requirements she has set up by asking the student to stand, and can be interpreted as a kind of empathetic stance. I argue that this shift to plain form, before the student has even spoken, imparts a sense that the group's expectations are lowered 
in the face of the activity. Suzuki Sensei does not expect that the student will get it right.

When Asou kun and another student, Katou kun, do supply possible answers, Suzuki Sensei does not work with them to help orient their perspective to theoretical situations which might clarify the English and lead them to a correct answer. There is no joint construction of correctness, which can then be raised to an objective level with the framing of desu/-masu. Suzuki Sensei does sum up a correct answer with the use of desu/-masu above in line 12 but she does so to ratify her own explanation of study as correct.

In the following, the use of honorific by both Suzuki Sensei and student in lines 2 and 3 indexes the official nature of the activity, announcing the reading of the next exercise. But in both prior and subsequent speech (line 1 and line 4 and on), both Suzuki Sensei and student use plain form. "Sarah" is the author. The arrows mark instances of desu/-masu form used in this segment.

(7)

1 S Sensei; ( ) hai, ja, ichiban, hai tsugi niban, ah, kore yomaseta hou ga iin da wa, ne, yes, so, number one, yes next number two, ah, here have read way S BE IP IP ne, sou da ne, ( ) ni ban, ni ban yonde mimashou, IP so BE IP number two number two read let's get

3 Tagawa; ja yomasete moraimasu, he studied hard in order to get a scholarship so allowed to read

4 S Sensei; chotto matte, Watanabe, kyoukasho motteru? (sonohen de) dareka mottetara, a little wait textbook have that area in someone have CON Sarah ni kashite, hhhhh, Sarah ni yonde morau, he doesn't have a text book,

$$
\text { IO loan IO read to get }
$$

8 Sarah; ah, on page fifty-eight?

9 S Sensei; ah actually I have no text book,

10 Sarah; oh, ok, I think, "he studied hard in order to get a scholarship,"

11 Tagawa; sonna fuu ni ienai yo, nihonjin damon! ((class laughs))

that way IO cannot read IP Japanese person BE

12 S Sensei; nannde yo, nannde yo, hai, jaa mou ikkai, jaa, Sarah ga yondara, repeat

why IP why IP yes so one more time so $\mathrm{S}$ read CON

shiyou ne, okay, please one more time,

let's do IP

1 S Sensei; ( ) yes, so, number one, yes next number two, ah it would be good to have this read, right, right, ( ) number two, let's read number two,

3 Tagawa; so, I am allowed to read, "he studied hard in order to get a scholarship,"

4 S Sensei; just a second, Watanabe, do you have a textbook? if anyone in that area has a textbook, loan it to Sarah, hhhhh, we'll have Sarah read it, he doesn't have a textbook ((students try to lend a textbook)) loan a textbook, someone (10.0) Sarah, ( ) the number (two) we studied for,

S Sensei; ah actually I have no text book,

10 Sarah; oh, ok, I think, "he studied hard in order to get a scholarship,"

11 Tagawa; I can't say it that way, I'm Japanese!

12 S Sensei; why not, why not, yes, so one more time, so, when Sarah reads it, let's repeat 
right, okay, please one more time,

With plain form in line 1, Suzuki sensei expresses the thought that it would be good to have the English sentence read ("yomaseta hou ga iin da"). Only lines 2 and 3 feature the use of desu/-masu where it frames the rote school practice of proposing to the class that they read sentence number two. A student also uses desu/-masu in line 3 to accept the request to read the sentence out loud, but he is interrupted by Suzuki Sensei as she proposes that someone hand me (Sarah) the textbook so that I can read it out loud (presumably since I'm a native speaker). The shift from the standard, school-like activity of requesting and receiving a response from a student to the activity of finding someone to hand me a textbook requires shifting from honorific back to plain form again in line 4. The desire to "have the sentence read," and subsequent talk having to do with requesting me to read and then reacting to my reading is entirely expressed using plain form. After I read the sentence at Suzuki Sensei's request in line 10, a student exclaims, using plain form, "sonna fuu ni ienai yo, nihonjin damon!" ("I can't say it that way, I'm Japanese!"). This makes the connection among plain form, a stance toward learning, and an authentic insider identity explicit.

While plain form at LAHS is almost never used in combination with interactional particles $n e$ and $y o$, it is quite common at THS. In the above excerpt it occurs in line 1 with the expression of insider desire to have a sentence read, rather than reading it oneself. And it occurs in the student's reaction to my reading, and then again, in Suzuki's response to this student. As a result participants construct a joint empathetic stance toward English. As a consequence, rather than foregrounding the informational content of the utterance, the plain form used here tends to foreground an affiliative, close relationship among speakers.

The final two examples are produced entirely in plain form, the default way of speaking in this class. Although they do not illustrate the effects of alternating desu/masu and plain form, they suggest the extent to which learning is problematized in this classroom and indentities constituted in opposition to the topic of learning, English. In the following example (8) the class has just removed their headphones after listening to an extended stream of English. Suzuki Sensei interprets students' facial expressions after she shuts off the player, and immediately aligns them all in an uncomprehending stance toward what they have just heard. This stance is then echoed by a student, Endo.

1 S sensei; uun wakannai yo ne muzukashii to omou yo yeah don't understand IP IP difficult QT think IP

(2 lines skipped)

4 Endo; cho kikitori nikui

really catch hard

1 S sensei; yeah (you/we/I) don't understand (I) think it's difficult

(2 lines skipped)

4 Endo; It's incredibly difficult to catch

The plain form combined with the colloquial nature of the speech in words like wakannai (a shortened form of wakaranai, "not understand") and cho (a slang word for 
"really") suggest the restricted code (Bernstein 1971) aspect of this type of classroom speech.

Similarly, in the following example (9) Suzuki Sensei is giving a brief talk about how to conceptually approach comprehension problems with English. She stresses the use of imagination to grasp the meaning of a word one is having trouble with, and justifies this approach with the explanation that warewarewa bokokugo ga eigo ja nai ("our mother tongue is not English"). This entire segment is produced in plain form. The single instance of an interactional particle, $s a$, is italicized.

(9)

1 S sensei; nantoka (1.0) sou hora dakara souyuuno wa souzou anyhow so listen because that say NOM T imagination

2 ryokude, hora tsunagun dakara, warewarewa bokokugo ga eigo (1.0) strength from, look connect Nom because, we T mother tongue $\mathrm{S}$ English [ja nain] dakara $s a$, souyatte tsunagun dakara, minna de motto tango [is not] because IP, so doing connect Nom because, everyone from more words

$4 \quad$ [(

5 dashite, hai ushiro

throw out, yes in the back

1 S sensei; anyhow (1.0) right look so this is (done) by using your imagination, look because it makes a connection, we (use imagination) to make a connection because our mother tongue [isn't] English, right, [((nods twice $))]$ everyone give more vocabulary, yes, next, in back

This segment also evidences a form of restricted code, expressing a sense of belonging in opposition to English language. Again, plain form, the default mode of this classroom, frames an insider's struggle with learning, rather than marking the analytical details of the material, as it does in classrooms at LAHS. Interactional particle $s a$ and the teacher's emphatic nod of the head cement this framing as a shared sentiment.

\section{Discussion and conclusions: Routine educational perspective-taking and social class identity}

Instead of conveying a sense of intimacy, the use of plain form at LAHS constitutes a problem-solving stance in which participants occupy an event situation, and its use indexes an information-focused interaction, free of any interpersonal interactional requirements of the immediate setting, and therefore able to make room for movement into theoretical realms where the use of English can be discussed, however briefly. Although this is a grammar class, fine distinctions in the meaning of words and structures cannot be understood without some reference to everyday use. Students' ability to perform well on tests would be impaired if they couldn't make some finegrained judgments about the use of certain words. During these brief theoretical moments, students are positioned within imaginary settings in order to ground meaning. By being ultimately framed with desu/-masu in subsequent teacher turns, their correct contributions are raised objectively to an authoritative, official level. The mixture of 
honorific and plain form at LAHS is an analytical practice, socializing students to be able to understand both facts about English grammar as well as its situated use. In the more rigorous activities, when translations are being performed, correct information is elicited and marked at a highly detailed level, and interaction remains largely impersonal. Students are thus being engaged in an elaborated code (Bernstein 1971), an orderly, detailed, and academic way of discussing textual meaning. As a consequence, they are being given access to English language free of judgments about the potential cultural implications (threats) of English influence in Japanese society. Teachers sometimes expressed such judgments "backstage" to me, but never within the classroom.

At THS, on the other hand, the alternation between desu/-masu and plain form serves to emphasize a distinction between participants' selves on the one hand, and the act of learning on the other. Desu/-masu frames speech that is concerned with overtly school-like activities where teacher and students act "in role." Plain form occurs most of the rest of the time, and expresses an insider's view that English is rather distant from ones true self, as in the student's exclamation, "I can't say it that way, I'm Japanese!" The ultimate goal, as Suzuki Sensei made clear to me on several occasions, is a "sense of accomplishment" (tassei kan), rather than an actual mastery of certain skills. Suzuki Sensei frequently stressed to me that I should understand that THS was not a "test preparation" institution, like LAHS, where she knew I was also conducting research. At THS, therefore, the alternation of plain form and desu/-masu constitutes a practice of highlighting and problematizing identity. The discourse constructed out of these classroom practices at THS bears some resemblance to Kondo's description of shitamachi identity in Tokyo and how individuals discursively orient themselves toward "Japaneseness," in part by making fun of the use of honorific language (1990). Similarly, in Suzuki Sensei's grammar classes, the use of desu/-masu is used only to index an intrapersonal distance from the school-like activities and roles associated with learning English, which nevertheless must be performed. At some level, this is not unlike Paul Willis's discussion of the discursive construction of a working class counter school culture in England (1977).

Of the operation of class culture in schools in England Paul Willis writes that it "is not a neutral pattern, a mental category, a set of variables impinging on the school from the outside. It comprises experiences, relationships, and ensembles of systematic types of relationship which not only set particular 'choices' and 'decisions' at particular times, but also structure, really and experientially, how these 'choices' come about and are defined in the first place" (1977: 1). Different routine, systematic relationships between participants and an object of study, English language, are being constituted during lessons at LAHS and THS. These ideological practices can be said to concretely shape students' opportunities and choices as types of Japanese citizens. In a global economy and a local educational system that increasingly value the ability to speak English, communicative competence in a second language - or at the very least, the ability to pass English portions of tough college entrance exams - is a key resource for students. Blommaert (1992) draws a distinction between the availability of communicative resources on the one hand, and access to them on the other. He writes, "Availability refers to the historical presence of resources, while access indicates the way in which these available resources are distributed among groups and individuals, by means of mechanisms of control such as education, political ideology, or law. A resource may thus be available in a society, but not accessible to all members of that 
society" (1992: 66). This paper has contributed to an analysis of how variable communicative competence in a foreign language is socialized. The creative ability of both plain form and desu/-masu to assume a variety of diverse roles in relation to context is a key resource for constituting dramatically different perspectives within English language classrooms.

\section{Acknowledgements}

The research reported in this article was made possible by a grant from The WennerGren Foundation for Anthropological Research. Subsequent research and writing was supported by a University of California Chancellor's Dissertation Year Fellowship.

\section{References}

Agha, Asif (1993) Grammatical and indexical convention in honorific discourse. Journal of Linguistic Anthropology 3.2: 131-163.

Bachnik, Jane M., and Charles J. Quinn (1994) Situated Meaning, Inside and Outside in Japanese Self, Society, and Language. Princeton: Princeton University Press.

Bernstein, B. (1971-75) Class, codes and control, 3 vols. London: Routledge and Kegan Paul.

Blommaert, Jan (1992) Codeswitching and the exclusivity of social identities: Some data from campus kiswahili. Journal of Multilingual and Multicultural Development 13.1-2: 57-70.

Brown, Penelope, and Stephen Levinson (1987) Politeness: Some Universals in Language Usage. Cambridge: Cambridge University Press.

Capps, Lisa, and Elinor Ochs (1995) Constructing Panic, The Discourse of Agoraphobia. Harvard University Press.

Cook, Haruko Minegishi (1996) The Japanese verbal suffixes as indicators of distance and proximity. In M. Putz, and R. Dirven (eds.), The Construal of Space in Language and Thought. Berlin: Mouton de Gruyter, pp. 3-27.

Cook, Haruko Minegishi (1997) The role of the Japanese masu form in caregiver-child conversation. Journal of Pragmatics 28: 695-718.

Cook, Haruko Minegishi (1998) Students' use of the impersonal style in a Japanese elementary school classroom. Crossroads of Language, Interaction, and Culture 1: 43-58.

Cook, Haruko Minegishi (1999) Situational meanings of Japanese social deixis: The mixed use of the masu and plain forms. Journal of Linguistic Anthropology 8.1: 87-110.

Cummings, William K. (1980) Education and equality in Japan. Princeton University Press. 
Dunn, Cynthia D. (1999) Public and private voices: Japanese style shifting and the display of affective intensity. In G. Palmer, and D. Occhi (eds.), The Languages of Sentiment. Amsterdam: John Benjamins Publishing Company, pp. 107-130.

Dunn, Cynthia D. (2005) Pragmatic functions of humble forms in Japanese ceremonial discourse. Journal of Linguistic Anthropology 15.2: 218-238.

Duranti, Alessandro (2009) The relevance of Husserl's theory to language socialization. Journal of Linguistic Anthropology 19.2: 205-226.

Geyer, Naomi (2008) Interpersonal functions of style shift: The use of plain and masu forms in faculty meetings. In K. Jones, and T. Ono (eds.), Style shifting in Japanese. Amsterdam: John Benjamins Publishing Company.

Giroux, Henry A. (1981) Ideology, Culture and the Process of Schooling. Philadelphia: Temple University Press.

Giroux, Henry A. (1983) Theory and Resistance in Education: A Pedagogy for the Opposition. Westport, Connecticut: Bergin \& Garvey.

Goto-Butler, Yuko (2005) Comparative perspectives towards communicative activities among elementary school teachers in South Korea, Japan and Taiwan. Language Teaching Research 9. 4: 423-446.

Husserl, Edmund (1989) Ideas Pertaining to a Pure Phenomenology and to a Phenomenological Philosophy. Second Book: Studies in the Phenomenology of Constitution. R. Rojcewicz and A. Schuwer (trans.), Dordrecht: Kluwer.

Ichikawa, Shogo (1991) Distinctive Features of Japanese Education. NIER Occasional Paper, National Institute for Educational Research.

Ike, Minoru (1995) A historical review of English in Japan (1600-1880). World Englishes 14: 1.

Ikuta, Shoko (1982) Speech level shift and conversational strategy in Japanese discourse. Language Sciences Volume 5: 1.

Jones, Kimberly, and Tsuyoshi Ono (2008) K. Jones and T. Ono (eds.), Style shifting in Japanese. Amsterdam and Philadelphia : John Benjamins Publishing Company.

Kinsui, Satoshi (2002) The influence of translation upon the historical development of the Japanese language. The UCLA Center for Japanese Studies Colloquium, April 29, 2002.

Kondo, Dorinne (1990) Crafting Selves, Power, Gender, and Discourses of Identity in a Japanese Workplace. Chicago: The University of Chicago Press.

Makino, Seiichi (1983) Speaker/listener-orientation and formality marking in Japanese. Gengo Kenkyuи 84: 126-145.

Maynard, Senko K. (1991) Pragmatics of discourse modality: A case of da and desu/masu forms in Japanese. Journal of Pragmatics 15: 551-582.

Maynard, Senko K. (1993) Discourse modality: Subjectivity, Emotion and Voice in the Japanese Language. Amsterdam: John Benjamins Publishing Company.

Maynard, Senko K. (1997) Shifting contexts: The sociolinguistic significance of nominalization in Japanese television news. Language in Society 26: 381-399. 
Meacham, Sarah S. (2004) Ideological complexity, national subjectivity, and the cultures of English in Tokyo high schools. Texas Linguistic Forum 47: 97-108, Proceedings of the Eleventh Annual Symposium about Language and Society. Austin.

Meacham, Sarah S. (2007) The educational soundscape: Participation and perception in Japanese high school English lessons. Mind, Culture, and Activity 14.3: 1-20.

Mehan, Hugh (1979) Learning lessons: Social organization in the classroom. Cambridge: Harvard University Press.

Ochs, Elinor (1993) Indexing Gender. In B.D. Miller (ed.), Sex and gender hierarchies. Cambridge: Cambridge University Press.

Ochs, Elinor, and Bambi B. Schieffelin (1984) Language acquisition and socialization: Three developmental stories. In R.A. Shweder, and R.A. LeVine (eds.), Culture theory: Essays on mind self, and emotion. Cambridge: Cambridge University Press.

Rogoff, Barbara (1990) Apprenticeship in Thinking, Cognitive Development in Social Context. Oxford: Oxford University Press.

Sapir, Edward (1924) Culture, genuine and spurious. Journal of Sociology 29: 401-429.

Shibatani, Masayoshi (1990) The Languages of Japan. Cambridge: Cambridge University Press.

Willis, Paul (1977) Learning to Labor, How Working Class Kids Get Working Class Jobs. New York: Columbia University Press.

SARAH S. MEACHAM is a linguistic and cultural anthropologist. Her research has focused on the situated interrelation of knowledge and identity, how knowing is a socio-culturally and interactionally constituted stance, and thus politically and morally weighted. She has researched the connection between English language learning and socioeconomic and national identity in Japanese society. This work has resulted in two prior publications. One investigates how different ways of hearing English within distinct educational institutions are connected to ideas about cultural identity, thus impacting the ways in which English is learned. Another piece argues that interaction within English language lessons across different institutions is a site for the construction of different forms of national identity. Although she continues to analyze the interactional data from learning settings in Japan, her more recent research considers the material and interactional contexts of literacy learning in the United States A recent piece in the Journal of Linguistic Anthropology identifies the impact of temporal cultures within classrooms on the way students interact with texts and with one another. She is also currently analyzing data collected during a two-year postdoctoral position working on a literacy reform initiative, investigating the way education reformers talk about teachers and how these characterizations impact their problem-solving process. She earned her Ph.D. in anthropology from the University of California, Los Angeles, and her A.B. in anthropology from Princeton University.

Address: 415 S. Cloverdale Ave. \#6, Los Angeles, CA90036, United States. E-mail:

smeacham@bigobvious.com 